Article

\title{
Breakfast in the United States: Food and Nutrient Intakes in Relation to Diet Quality in National Health and Examination Survey 2011-2014. A Study from the International Breakfast Research Initiative
}

\author{
Adam Drewnowski ${ }^{1, *}$, Colin D. Rehm ${ }^{2}$ and Florent Vieux ${ }^{3}$ \\ 1 Center for Public Health Nutrition, University of Washington, Box 353410, Seattle, WA 98195, USA \\ 2 Albert Einstein College of Medicine, Montefiore Medical Center, New York, NY 10467, USA; \\ colin.rehm@gmail.com \\ 3 MS-Nutrition, 27 bld Jean Moulin Faculté de Médecine la Timone, Laboratoire C2VN, CEDEX 5, \\ 13385 Marseille, France; florent.vieux@ms-nutrition.com \\ * Correspondence: adamdrew@uw.edu; Tel.: +1-206-543-1730
}

Received: 5 August 2018; Accepted: 27 August 2018; Published: 1 September 2018

\begin{abstract}
The contribution of breakfast to diet quality (DQ) can inform future dietary guidelines. This study examined breakfast nutrition in relation to overall DQ, using dietary data from the first reported day of the National Health and Examination Survey (NHANES) 2011-2014 $(n=14,488)$. Relative DQ was assessed using the Nutrient Rich Foods Index (NRF9.3) and the USDA Healthy Eating Index 2015 (HEI 2015). The sample was stratified by NRF9.3 tertiles and by age and socioeconomic groups. Four out of 5 NHANES participants had breakfast on the day of the interview. Breakfast provided 19-22\% of dietary energy depending on age. Breakfast intakes of complex carbohydrates and total sugars were proportionately higher and intakes of protein and fats were lower relative to breakfast energy intakes. Breakfast provided more that $20 \%$ of daily intakes of B vitamins, vitamins $\mathrm{A}$ and $\mathrm{D}$, folate, calcium, iron, potassium and magnesium. Eating breakfast was associated with higher NRF9.3 DQ scores. Breakfasts associated with the top tertile of NRF9.3 scores had less added sugars and fats than those associated with the bottom tertile. Such breakfasts had more fruit and juices, more whole grain products, more milk and yogurt and less meat and eggs. Breakfast patterns and food choices that favored fruit, whole grains and dairy were associated with healthiest diets.
\end{abstract}

Keywords: breakfast; dietary intake; nutrition; dietary quality; NRF9.3 index; USDA HEI 2015 index

\section{Introduction}

Breakfasts that provide more nutrients than calories can be viewed as nutrient-rich meals [1-4]. Eating breakfast has been associated with higher-quality diets and with higher intakes of key nutrients and desirable food groups [5,6]. By contrast, skipping breakfast has been linked to lower-quality diets, lower cognitive performance and a host of negative health outcomes [7-15]. The International Breakfast Research Initiative (IBRI) aimed to identify breakfast patterns associated with highest quality diets using nationally representative data from six countries: Canada, Denmark, France, Spain, UK and the US.

Analyses of NHANES 2001-2008 data showed that about 19\% of the US population skipped breakfast altogether [4]. The rest exhibited as many as 12 breakfast "patterns" that typically included grain products, fruit juice, milk, whole fruit, sweets, meat and eggs and coffee or tea [4]. In some studies, the consumption of selected breakfast components (e.g., ready to eat or RTE cereals) was 
associated with higher-quality diets [16-19]. What food groups make for a healthy breakfast pattern across countries and consumer subgroups continues to be a topic of research interest $[1,5,20,21]$.

This study examined the notion that the US breakfast is a nutrient-rich meal by assessing the contribution of breakfast to daily energy and nutrient intakes among US children and adults. Breakfast patterns associated with different-quality diets were then examined in detail. The goal was to arrive at an optimal combination of breakfast foods that could be the basis of future dietary recommendations and guidelines.

\section{Materials and Methods}

\subsection{Study Population \& Dietary Data}

Analyses were based on the first day of dietary intakes in the 2011-2012 and 2013-2014 cycles of the nationally representative National Health and Nutrition Examination Survey (NHANES) [22,23]. Data were available for 14,488 children, adolescents and adults aged $\geq 6 \mathrm{y}$. The sample included 2511 children (ages 6-12 y); 1546 adolescents (ages 13-17 y); 6594 adults (ages 18-54 y) and 3837 older adults (ages $\geq 55 \mathrm{y}$ ).

The first 24-h recall in the NHANES was completed in-person at the Mobile Examination Center with a trained interviewer. The 24-h recall queries all foods/beverages consumed by participants from midnight-to-midnight on the previous day [22,23]. Dietary supplements were excluded. Breakfast was defined as the self-reported "breakfast/desayuno" and brunch. An energy threshold of $50 \mathrm{kcal}$ was imposed. Breakfast skippers were defined as having no breakfast or an eating episode of $<50 \mathrm{kcal}$.

The population sample was stratified by four age groups (6-12 y, 13-17 y, 18-54 y and $\geq 55 \mathrm{y})$ and six race/ethnicity groups (non-Hispanic white, non-Hispanic black, Mexican-American, other Hispanic, Asian and other/mixed race). Education was defined as: $<$ High School $(<12 \mathrm{y})$, High School (12 y); Some college (12-16 y) and >College ( $>16 \mathrm{y})$. Income to poverty ratio (IPR) cut-points were set at: $<1.3 ; 1.3-1.849 ; 1.85-2.99 ;>3$.

\subsection{Measures of Diet Quality}

The Nutrient Rich Foods (NRF) index was the principal measure of nutrient density of the total diet $[19,24,25]$. Its development and validation, with respect to other measures of diet quality and long-term health outcomes, have been described in the literature [24-27]. The present NRF9.3 variant applied to total diets was based on 9 qualifying nutrients (NR) and 3 disqualifying nutrients (LIM). Reference daily values (DVs) were based on the US Food and Drug Administration (FDA) and other standards $[19,24]$. The qualifying nutrients and standard reference amounts were as follows: protein (50 g), fiber (28 g), vitamin A (900 RAE), vitamin C (90 mg), vitamin D (20 mcg), calcium (1300 mg), iron $(18 \mathrm{mg})$, potassium $(4700 \mathrm{mg})$ and magnesium $(420 \mathrm{mg})$. The 3 disqualifying nutrients and maximum recommended values (MRVs) were: added sugar (50 g), saturated fat (20 g) and sodium $(2300 \mathrm{mg})$. The NRF9.3 was calculated as follows:

$$
\text { NRF9.3 }=(\mathrm{NR}-\mathrm{LIM}) \times 100
$$

with

$$
\mathrm{NR}=\sum_{i=1}^{9} \frac{\text { Intake }_{i} / \text { Energy } \times 2000}{D V_{i}}
$$

and

$$
\mathrm{LIM}=\sum_{i=1}^{3} \frac{\text { Intake }_{i} / \text { Energy } \times 2000}{M R V_{i}}-1
$$

where intake $_{i}$ is the intake of each nutrient $i$ and $D V_{i}$ is the reference daily value for that nutrient.

In NR calculation, each daily nutrient intake $i$ was adjusted for $2000 \mathrm{kcal}$ and expressed in percentage of DV. Following past protocol, percent DVs for nutrients were truncated at 100, so that an 
excessively high intake of one nutrient could not compensate for the dietary inadequacy of another. In LIM, only the share in excess of the recommended amount was considered.

The development and validation of the NRF family of nutrient density scores are all well-documented in the literature [26,27]. In the present adaptation, vitamin $\mathrm{D}$, a nutrient of public health concern [28-30], replaced vitamin E. Fiber, vitamin D, calcium, magnesium and potassium were all identified in the 2010 Dietary Guidelines for Americans as nutrients of concern [29]. The NRF score was adjusted for energy intakes, analogous with the recent versions of the USDA Healthy Eating Index (HEI), a federal measure of diet quality [31].

The HEI-2015 is the latest iteration of the USDA diet quality measurement tool, specifically designed to monitor compliance with the 2015 Dietary Guidelines for Americans [31]. The HEI-2015 is a 100-point scale where the adequacy components are total fruits (5 points), whole fruits (5), total vegetables (5), greens and beans (5), whole grains (5), dairy (10), total protein (5), seafood and plant protein (5) and fatty acid ratio (10); the moderation components are refined grains (10), sodium (10) added sugars (10) and saturated fats (10). HEI 2015 values were calculated using the USDA Food Patterns Equivalents Database (FPED) [32]. Both NRF9.3 and HEI 2015 were corrected for dietary energy (1000 kcal for HEI and $2000 \mathrm{kcal}$ for NRF).

\subsection{Analytical Strategy}

Energy and nutrient intakes for NHANES participants were calculated using the Food and Nutrient Database for Dietary Studies 2011-2014. The primary nutrient outcome measures were selected based on their overall importance to current dietary recommendations [29]. Some of the nutrients were in the NRF model but some were not. For example, fiber, vitamin D, calcium, magnesium and potassium (all in the NRF model) were identified in the 2010 Dietary Guidelines for Americans as nutrients of concern [29]. Iron (also in the model) was identified as a nutrient of concern for adolescent girls and women capable of becoming pregnant. By contrast, the NRF model did not include nutrients of concern such as folic acid (women capable of becoming pregnant) or vitamin B12 (older adults) [19,24]. Breakfast food groups of interest were based on reported consumption frequency by children and adults and included milk, whole fruit and fruit juices, whole grains and low-fat dairy, soy, nuts and legumes, as well as ready to eat cereals (RTEC).

All analyses were conducted using SAS software, Version 9.4 (SAS Institute Inc., Cary, NC, USA) and are representative of the US population. Differences between proportions were tested using $X^{2}$ tests. Differences in quantitative variables (such as intakes) were tested using Generalized Linear Models, adjusted as appropriate (without and with adjustment for energy at breakfast as well as energy at breakfast and socio-demographics characteristics). Pearson coefficient correlations between NRF9.3 and HEI score, as well as between NRF9.3 and all HEI subscores, were estimated. The statistical significance level was set at $p$-value $<0.05$.

\subsection{Data Availability and Ethical Approval}

The necessary Institutional Review Board (IRB) approval for NHANES had been obtained by the National Center for Health Statistics (NCHS) [33]. Adult participants provided written informed consent. Parental/guardian written informed consent was obtained for children. Children/adolescents $\geq 12$ y provided additional written consent. All NHANES data are publicly available on the NCHS and USDA websites [22,23]. Per University of Washington (UW) policies, public data do not involve "human subjects" and their use requires neither IRB review nor an exempt determination. Such data may be used without any involvement of the Human Subjects Division or the UW Institutional Review Board. 


\section{Results}

Table 1 shows that out of 4057 children, 3296 (82.0\%) ate breakfast on the first day of the NHANES survey and $761 \mathrm{did}$ not (18.0\%). Out of 10,431 adults, $8269(80.3 \%)$ ate breakfast and $2162(19.7 \%)$ did not. Those figures were based on the $<50 \mathrm{kcal}$ breakfast energy threshold. With the threshold removed, $17.4 \%$ of children and $15.2 \%$ of adults ate no breakfast at all.

Breakfast consumption patterns showed a bimodal distribution by age. Most likely to eat breakfast (87.5\%) were young children and older adults. Only 3 out of 4 adolescents and young adults ate breakfast. Among children, most likely to eat breakfast were Asians, Whites and other Hispanics. Least likely to eat breakfast were non-Hispanic Blacks. Among adults, most likely to eat breakfast were non-Hispanic Whites, other Hispanics and Asians. Least likely to eat breakfast were non-Hispanic Blacks. Breakfast consumption increased sharply with household incomes for children and adults and with education and incomes for adults. Higher-income groups and college graduates were most likely to eat breakfast.

Subsequent analyses were conducted among breakfast consumers only. Figure 1 shows the percent contribution of breakfast to total daily energy and nutrient intakes by age group. For the whole NHANES sample, mean and median energy intakes at breakfast were $447 \mathrm{kcal} / \mathrm{d}$ and $366 \mathrm{kcal} / \mathrm{d}$, respectively. Breakfast accounted for approximately $20 \%$ of daily energy intakes. The exact percentages were $19.2 \%$ of energy intakes for children, $21.7 \%$ for adolescents; $20.0 \%$ for adults and $21.8 \%$ for older adults.

Breakfast supplied just $<20 \%$ of daily protein and total fat, approximately $20 \%$ of fiber and saturated fatty acids (SFA) and around $25 \%$ of total sugars and between $20 \%$ and $22 \%$ of added sugar, depending on age. Older adults consumed more dietary fiber, carbohydrates and total and added sugars at breakfast than did children and adolescents.

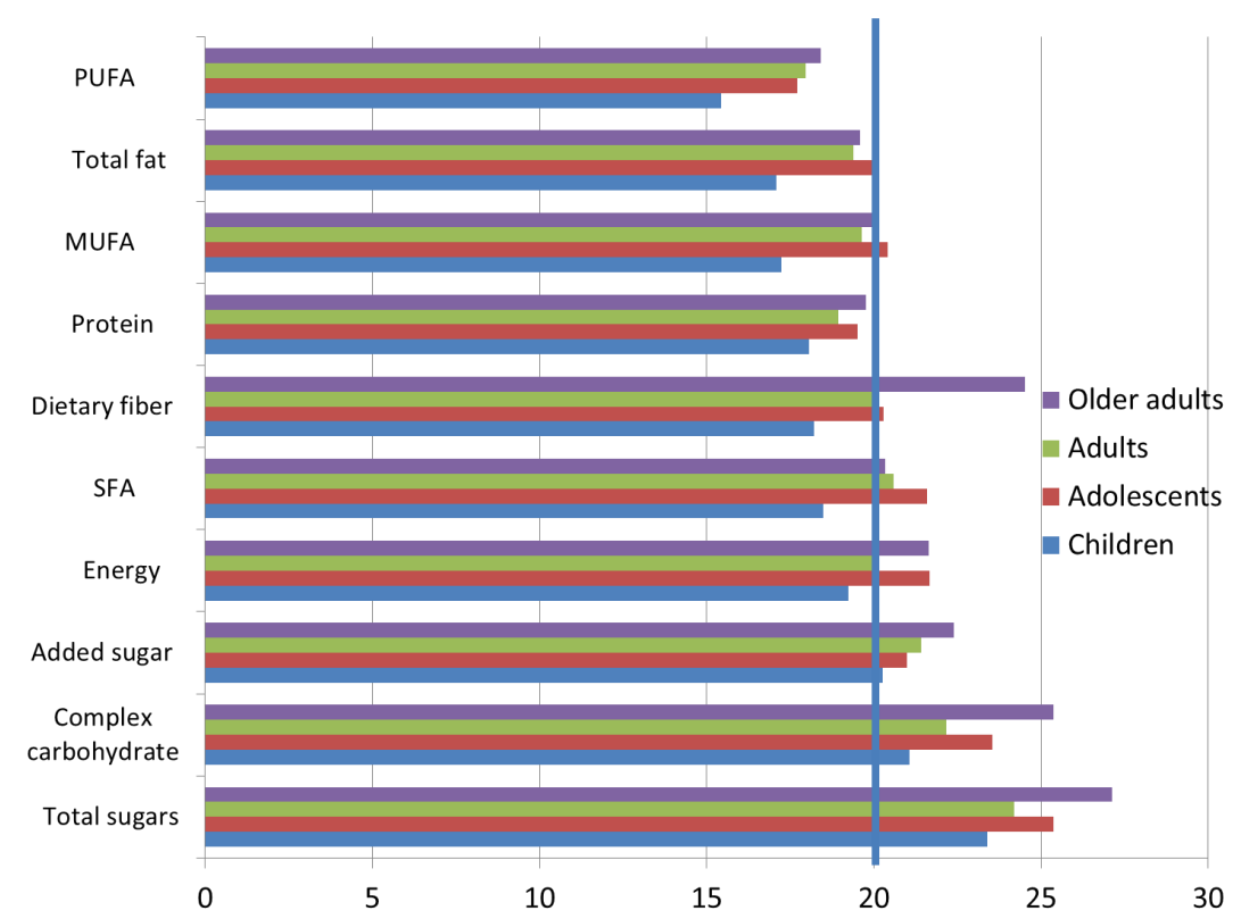

Figure 1. Percent contribution of breakfast to macronutrient intakes relative to energy intakes among breakfast consumers. PUFA stands for Polyunsaturated fatty acids, MUFA stands for Monounsaturated fatty acids, SFA stands for Saturated fatty acids. The $20 \%$ cutoff is indicated by a vertical line. 
Table 1. Frequency (\%) and $95 \%$ confidence limits of breakfast consumption by age group and by key demographics.

\begin{tabular}{|c|c|c|c|c|c|c|}
\hline & \multicolumn{3}{|c|}{ Children/Adolescents $(N=4057)$} & \multicolumn{3}{|c|}{ Adults/Older Adults $(N=10,431)$} \\
\hline & All $(N=4057)$ & $\begin{array}{c}\text { Skippers } N=761 \\
(18 \%)\end{array}$ & $\begin{array}{c}\text { Consumers } N=3296 \\
(82 \%)\end{array}$ & All $(N=10431)$ & $\begin{array}{c}\text { Skippers } N=2162 \\
(19.7 \%)\end{array}$ & $\begin{array}{c}\text { Consumers } N=8269 \\
(80.3 \%)\end{array}$ \\
\hline \multicolumn{7}{|l|}{ Age (y) } \\
\hline $6-13$ & 2511 & $12.53(10.29-14.76)$ & $87.47(85.24-89.71)$ & & & \\
\hline $13-18$ & 1546 & $25.76(21.71-29.81)$ & 74.24 (70.19-78.29) & & & \\
\hline $18-55$ & & & & 6594 & $23.51(21.38-25.63)$ & 76.49 (74.37-78.62) \\
\hline \multirow{2}{*}{$>55$} & & & & 3837 & $12.5(10.89-14.11)$ & $87.5(85.89-89.11)$ \\
\hline & \multicolumn{4}{|c|}{$<0.001$} & \multicolumn{2}{|c|}{$<0.001$} \\
\hline \multicolumn{7}{|l|}{ Gender } \\
\hline Male & 2073 & $17.68(15.18-20.18)$ & $82.32(79.82-84.82)$ & 5092 & $21.41(19.78-23.05)$ & $78.59(76.95-80.22)$ \\
\hline \multirow{2}{*}{ Female } & 1984 & $18.36(15.13-21.59)$ & $81.64(78.41-84.87)$ & 5339 & $18.04(15.9-20.18)$ & $81.96(79.82-84.1)$ \\
\hline & \multicolumn{3}{|c|}{0.66} & & \multicolumn{2}{|c|}{$<0.005$} \\
\hline \multicolumn{7}{|l|}{ Race/ethnicity } \\
\hline Non-Hispanic White & 1010 & $16.47(12.87-20.07)$ & $83.53(79.93-87.13)$ & 4225 & $17.43(15.5-19.35)$ & $82.57(80.65-84.5)$ \\
\hline Non-Hispanic Black & 1119 & $26.21(21.86-30.57)$ & $73.79(69.43-78.14)$ & 2443 & $27.09(24.44-29.74)$ & $72.91(70.26-75.56)$ \\
\hline Mexican American & 854 & $20.35(17.17-23.53)$ & $79.65(76.47-82.83)$ & 1252 & $24.28(19.98-28.58)$ & $75.72(71.42-80.02)$ \\
\hline Asian & 415 & $12.87(7.64-18.11)$ & 87.13 (81.89-92.36) & 1199 & $20.56(17.18-23.94)$ & $79.44(76.06-82.82)$ \\
\hline Other Hispanic & 424 & $16.46(13.00-19.92)$ & $83.54(80.08-87.00)$ & 984 & $19.61(15.52-23.7)$ & $80.39(76.3-84.48)$ \\
\hline \multirow{2}{*}{ Other/mixed race } & 235 & $10.38(4.30-16.47)$ & $89.62(83.53-95.7)$ & 328 & $26.15(20.72-31.58)$ & $73.85(68.42-79.28)$ \\
\hline & \multicolumn{3}{|c|}{$<0.001$} & & \multicolumn{2}{|c|}{$<0.001$} \\
\hline \multicolumn{7}{|l|}{ Family IPR ${ }^{1,2}$} \\
\hline$<1.3$ & 1739 & $22.97(19.92-26.01)$ & $77.03(73.99-80.08)$ & 3445 & $26.66(23.83-29.5)$ & 73.34 (70.5-76.17) \\
\hline $1.3-1.849$ & 498 & $20.92(15.81-26.03)$ & 79.08 (73.97-84.19) & 1176 & $20.29(16.71-23.87)$ & $79.71(76.13-83.29)$ \\
\hline $1.85-2.99$ & 561 & 22.79 (15.75-29.84) & 77.21 (70.16-84.25) & 1515 & $19.88(16.74-23.02)$ & $80.12(76.98-83.26)$ \\
\hline \multirow{2}{*}{$\geq 3.0$} & 996 & $9.93(6.70-13.17)$ & 90.07 (86.83-93.3) & 3511 & $15.46(13.42-17.5)$ & $84.54(82.5-86.58)$ \\
\hline & \multicolumn{3}{|c|}{$<0.001$} & & \multicolumn{2}{|c|}{$<0.001$} \\
\hline \multicolumn{7}{|l|}{ Education $^{3}$} \\
\hline$<$ High school & & & & 2130 & $24.58(21.49-27.67)$ & $75.42(72.33-78.51)$ \\
\hline High school & & & & 2149 & $20.3(17.59-23.01)$ & 79.7 (76.99-82.41) \\
\hline Some college & & & & 3040 & 22.08 (19.77-24.39) & $77.92(75.61-80.23)$ \\
\hline \multirow{2}{*}{$\geq$ College graduate } & & & & 2522 & $12.98(10.73-15.23)$ & 87.02 (84.77-89.27) \\
\hline & & & & & \multicolumn{2}{|c|}{$<0.001$} \\
\hline
\end{tabular}

$1 \overline{\text { IPR stands for Income to poverty ratio; }{ }^{2} \text { In children (resp in adults), } 263 \text { (resp. 784) missing IPR were removed from the analysis; }{ }^{3} \text { In adults, } 590 \text { missing education information were }}$ removed from the analysis. 
Figure 2 shows percent contribution of breakfast to total dietary energy and micronutrient intakes by age group. Although the energy contribution was about $20 \%$, breakfast provided substantially more than $20 \%$ of daily magnesium, potassium, phosphorus, niacin, vitamin C, zinc, calcium, thiamin, vitamin B6, iron, folate, riboflavin, vitamin A, folate, vitamin B12, vitamin D and retinol. For all age groups, breakfast provided $>40 \%$ of daily vitamin D. While the percentage of sodium was $<20 \%$, the percentage of cholesterol from breakfast was in the order of $30 \%$.

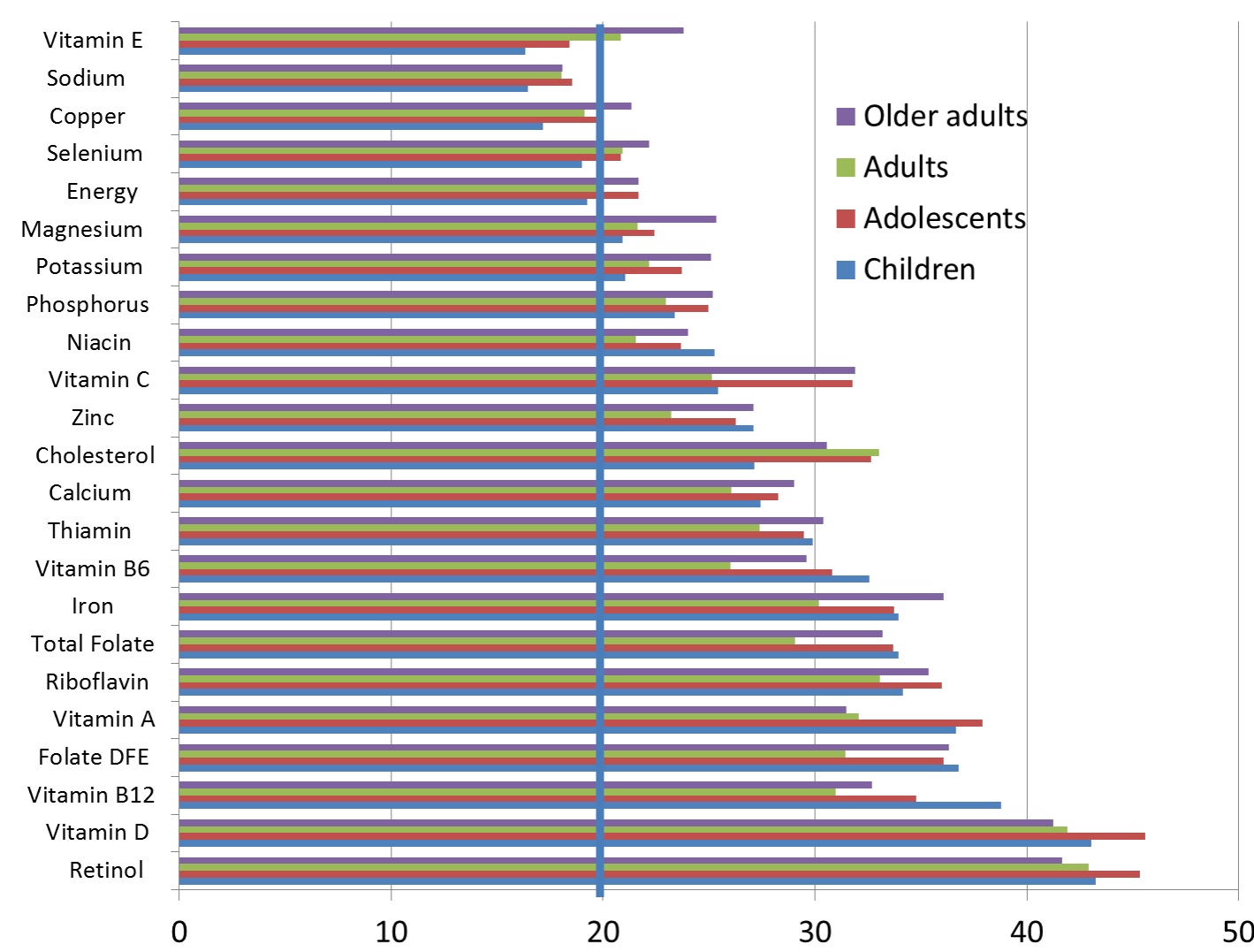

Figure 2. Percent contribution of breakfast to micronutrient intakes relative to energy intakes among breakfast consumers. The $20 \%$ cut point is indicated by the vertical line.

\subsection{Measures of Diet Quality-NRF9.3}

Figure 3 summarizes the construction of the NRF9.3 score, used here as a measure of nutrient density of the total diet. The NRF9.3 was adjusted per $2000 \mathrm{kcal}$, as detailed above. Separate panels show the NR subscore, composed of nutrients to encourage and the LIM subscore, composed of nutrients to limit. Figure 3 shows that percent daily values for index nutrients rose with tertiles of the NRF9.3 score, whereas the LIM subscores, to the contrary, decreased. As expected, going from the lowest (T1) to the highest tertile (T3) of NRF9.3 scores was associated with an increase in percent DVs of nutrients to encourage and a corresponding decrease in percent MRVs of nutrient to limit [24,27]. 

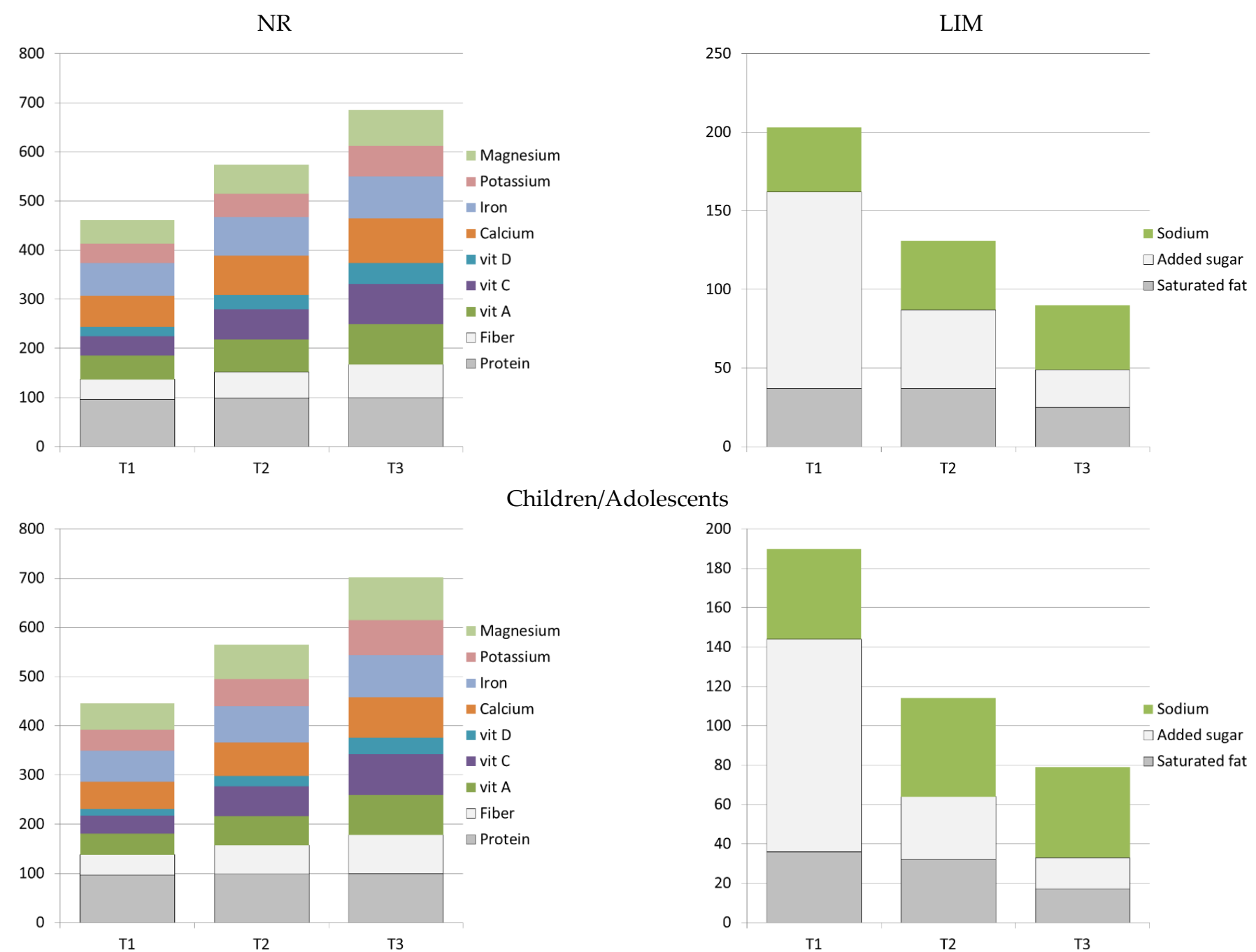

Children/Adolescents

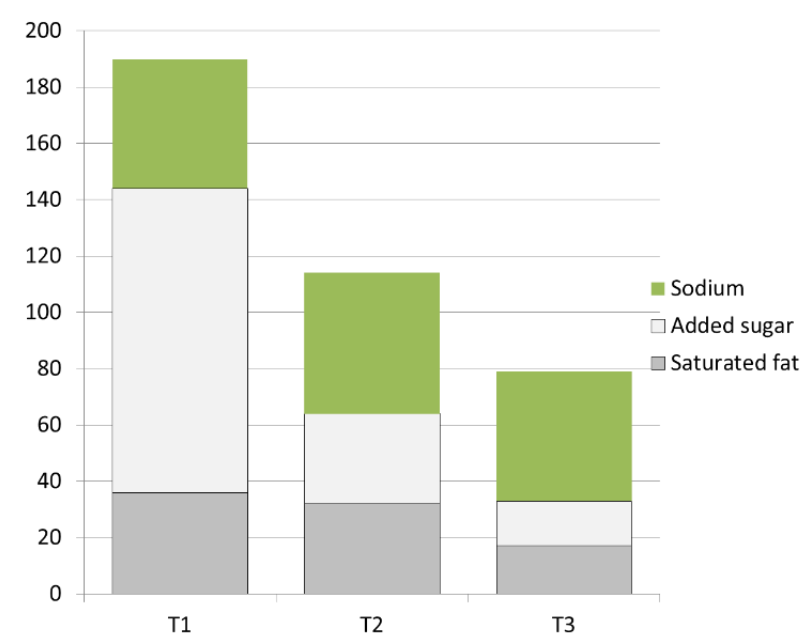

Adults/Older Adults

Figure 3. Nutrient subscores of the Nutrient Rich Index (NRF9.3) by age group and by tertiles of total NRF9.3 scores. 
The correlation between NRF9.3 scores and HEI 2015 scores based on the entire population aged $>2$ was statistically significant, $r=0.43$. The correlation between NRF9.3 scores and HEI subscores was statistically significant for most HEI components $(r=0.2$ to $r=0.34)$ and was strongest for added sugars, dairy, whole fruit and total fruit. Previous studies have shown that HEI scores were sensitive to age, gender and sociodemographic characteristics of NHANES study participants.

Table 2 shows mean DQ NRF9.3 scores for NHANES breakfast consumers by age, gender and sociodemographic characteristics. First, there was a bimodal effect of age-highest quality diets were consumed by children and by older adults; by contrast, adolescents had lowest-quality diets, consistent with many other reports [34,35]. Gender effects depended on age; whereas no gender differences were observed for children or adolescents, adult women had more nutrient-dense diets than did men.

Table 2. Mean $( \pm \mathrm{SE})$ NRF 9.3 scores for breakfast consumers by age and socio-demographics.

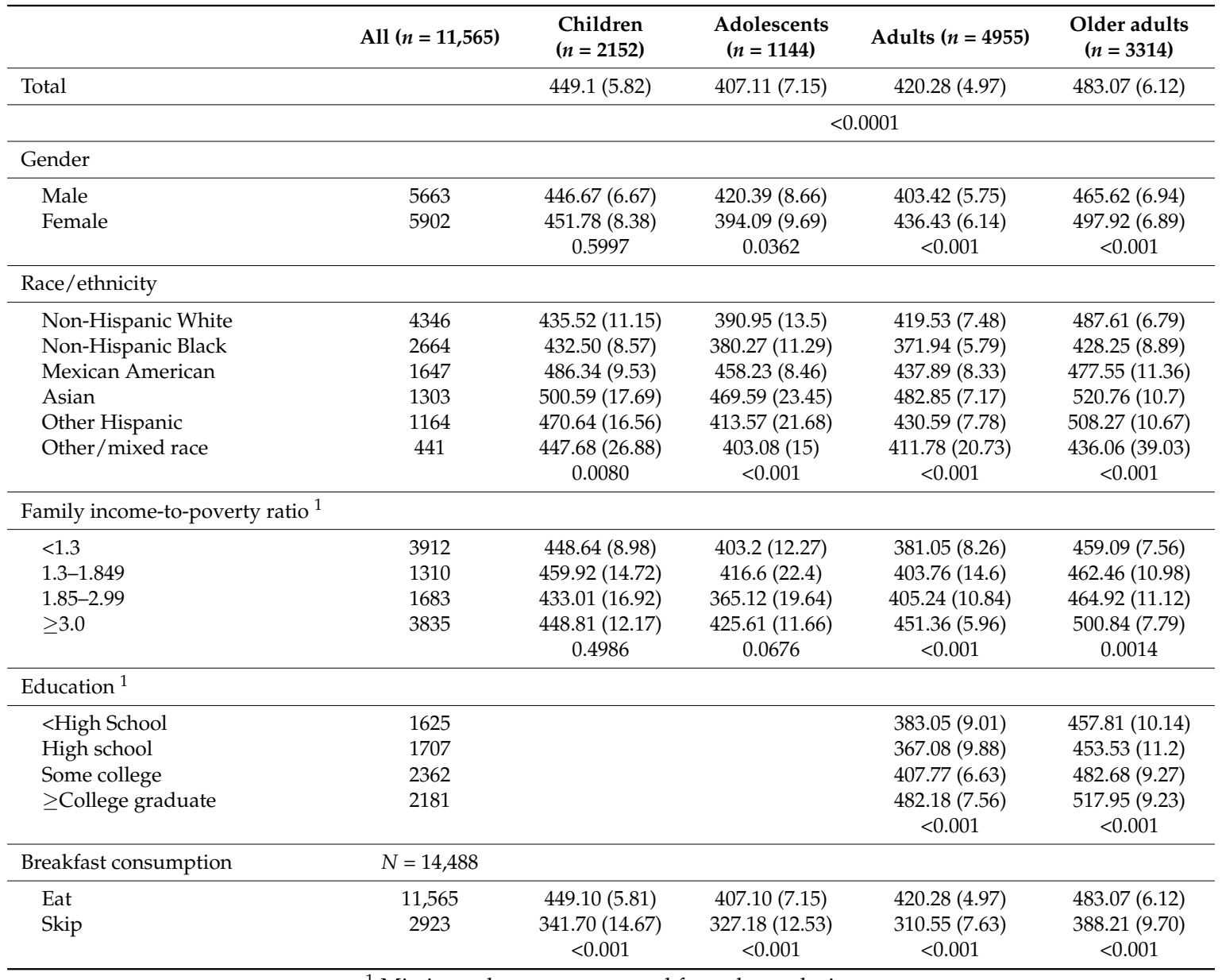

${ }^{1}$ Missing values were removed from the analysis.

The most nutrient-dense diets were consumed by Asians and other Hispanics. Non-Hispanic Blacks had lowest quality diets at every age. Diet quality of adults greatly improved with education and with household incomes. An income gradient for children was not observed. Differences in NRF scores by education and incomes were far greater than those observed by race/ethnicity.

Skipping breakfast had profound effects on NRF9.3 scores in univariate analyses. For children the difference was 107 points (Consumers $=449$; skippers $=342$ ); for adolescents, the difference was 80 points (Consumers $=407$; skippers $=327$ ); for adults, it was 110 points (Consumers $=420$; skippers $=310$ ) and for older adults the difference was 95 points (Consumers $=483$; skippers $=388$ ). 


\subsection{Breakfast Patterns by Tertiles of NRF9.3 Diet Quality Scores}

Figure 4 shows the macronutrient composition of breakfasts associated with tertiles of NRF9.3 scores. Breakfasts associated with better diets had much less added sugar and less fat but more carbohydrate and slightly more protein.

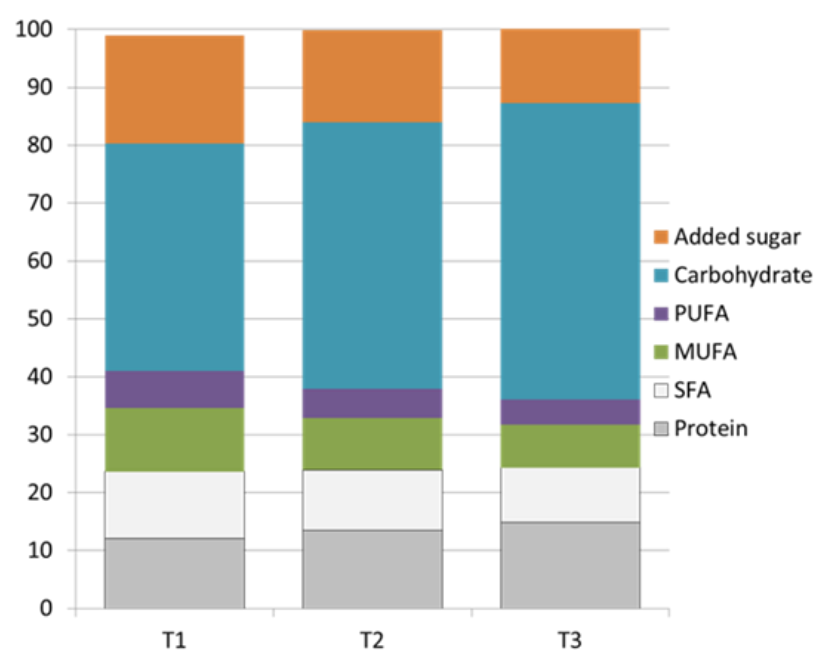

Children/Adolescents

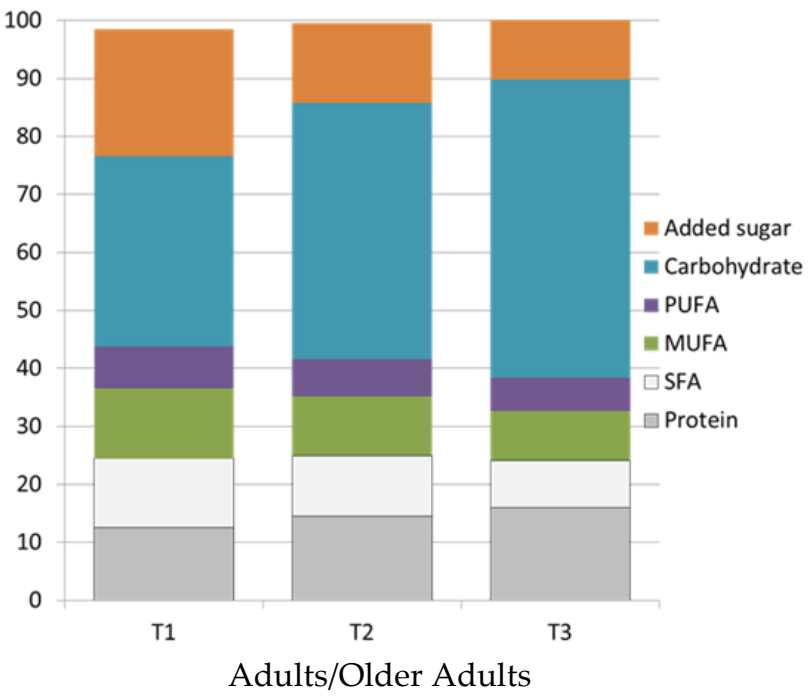

Figure 4. Distribution of breakfast macronutrients by tertiles of NRF9.3 diet quality score. PUFA stands for Polyunsaturated fatty acids, MUFA stands for Monounsaturated fatty acids, SFA stands for Saturated fatty acids.

The amounts of specific food groups consumed by diet quality tertiles are shown in Table 3, separately for children and for adults. First, higher-quality diets were associated with higher consumption of citrus fruit, juice and other fruits, whole grains and milk and yogurt. The consumption of citrus fruit, juice and other fruits doubled or tripled. The consumption of refined grains was cut in half but the consumption of whole grains almost tripled. Higher-quality diets were associated with lower consumption of refined grains, breakfast meats, eggs and cheese. Meat, poultry and seafood were substantially reduced; there was an increase in consumption of soy, nuts and legumes. The consumption of milk and yogurt increased, cheese dropped slightly. Solid fats were sharply reduced. Among adults, higher quality diets were associated with higher breakfast consumption of soy, nuts and legumes. 
Table 3. Amounts of selected food groups consumed at breakfast across tertiles of NRF 9.3 score by age group. Data for breakfast consumers only.

\begin{tabular}{|c|c|c|c|c|c|c|c|c|c|c|c|c|}
\hline & \multicolumn{6}{|c|}{ Children/Adolescents $(N=3296)$} & \multicolumn{6}{|c|}{ Adults/Older Adults $(N=8269)$} \\
\hline & T1 & T2 & T3 & $p^{*}$ & $p^{* *}$ & $p^{* * *}$ & T1 & T2 & T3 & $p^{*}$ & $p^{* *}$ & $p^{* * *}$ \\
\hline Citrus fruits $\dagger$ & $0.02(0)$ & $0.04(0.01)$ & $0.07(0.02)$ & 0.0104 & 0.015 & 0.0058 & $0.02(0)$ & $0.06(0.01)$ & $0.1(0.01)$ & $<0.001$ & $<0.001$ & $<0.001$ \\
\hline Juice (cup) † & $0.09(0.01)$ & $0.19(0.02)$ & $0.21(0.02)$ & $<0.001$ & $<0.001$ & $<0.001$ & $0.07(0.01)$ & $0.16(0.02)$ & $0.17(0.01)$ & $<0.001$ & $<0.001$ & $<0.001$ \\
\hline Other fruits $\dagger$ & $0.06(0.02)$ & $0.09(0.01)$ & $0.12(0.01)$ & 0.0325 & 0.033 & 0.0343 & $0.06(0)$ & $0.13(0.01)$ & $0.24(0.01)$ & $<0.001$ & $<0.001$ & $<0.001$ \\
\hline Whole grains $\ddagger$ & $0.18(0.02)$ & $0.3(0.03)$ & $0.47(0.03)$ & $<0.001$ & 0.000 & $<0.001$ & $0.22(0.02)$ & $0.47(0.03)$ & $0.7(0.03)$ & $<0.001$ & $<0.001$ & $<0.001$ \\
\hline Refined grains $\ddagger$ & $1.63(0.06)$ & $1.24(0.07)$ & $0.81(0.04)$ & $<0.001$ & 0.000 & $<0.001$ & $1.54(0.04)$ & $1.28(0.04)$ & $0.79(0.03)$ & $<0.001$ & $<0.001$ & $<0.001$ \\
\hline Meat/poultry/fish $\ddagger$ & $0.41(0.05)$ & $0.29(0.03)$ & $0.1(0.01)$ & $<0.001$ & 0.000 & $<0.001$ & $0.61(0.03)$ & $0.38(0.03)$ & $0.16(0.01)$ & $<0.001$ & $<0.001$ & $<0.001$ \\
\hline Eggs $\ddagger$ & $0.30(0.03)$ & $0.29(0.03)$ & $0.2(0.03)$ & 0.0457 & 0.545 & 0.5191 & $0.44(0.03)$ & $0.44(0.02)$ & $0.31(0.03)$ & 0.0023 & $<0.001$ & 0.0098 \\
\hline Soy, nuts, legumes $\ddagger$ & $0.06(0.01)$ & $0.05(0.01)$ & $0.09(0.02)$ & 0.1455 & 0.047 & 0.0738 & $0.13(0.02)$ & $0.19(0.02)$ & $0.31(0.02)$ & $<0.001$ & $<0.001$ & $<0.001$ \\
\hline Milk + & $0.41(0.03)$ & $0.6(0.03)$ & $0.74(0.03)$ & $<0.001$ & 0.000 & $<0.001$ & $0.23(0.01)$ & $0.35(0.02)$ & $0.52(0.01)$ & $<0.001$ & $<0.001$ & $<0.001$ \\
\hline Yogurt + & $0.01(0)$ & $0.01(0)$ & $0.03(0.01)$ & 0.0312 & 0.038 & 0.0439 & $0.02(0)$ & $0.03(0)$ & $0.04(0.01)$ & $<0.001$ & $<0.001$ & 0.0027 \\
\hline Cheese $t$ & $0.07(0.01)$ & $0.08(0.01)$ & $0.05(0.01)$ & 0.0217 & 0.393 & 0.3791 & $0.13(0.01)$ & $0.1(0.01)$ & $0.05(0)$ & $<0.001$ & $<0.001$ & $<0.001$ \\
\hline
\end{tabular}

* Unadjusted $p$-value; ${ }^{* *} p$-value adjusted for total energy at breakfast; *** $p$-value adjusted for energy at breakfast, ethnicity, income to poverty ratio, education (adults only) and gender; † Units for citrus fruits, juice, other fruits, milk, yogurt and cheese are cup-equivalents; † Units for whole grains, refined grains, meat/poultry/fish (MPF), eggs, soy, nuts and legumes are ounce-equivalents. 
Percentages of breakfast consumers of specific food groups by diet quality tertiles are shown in Figure 5. First, higher quality diets were associated with more children and adults consuming citrus fruit, juice and other fruits, whole grains and milk and yogurt at breakfast. Higher quality diets were associated with fewer people consuming refined grains, breakfast meats, eggs and cheese. Higher quality diets were associated with more adults consuming soy, nuts and legumes.
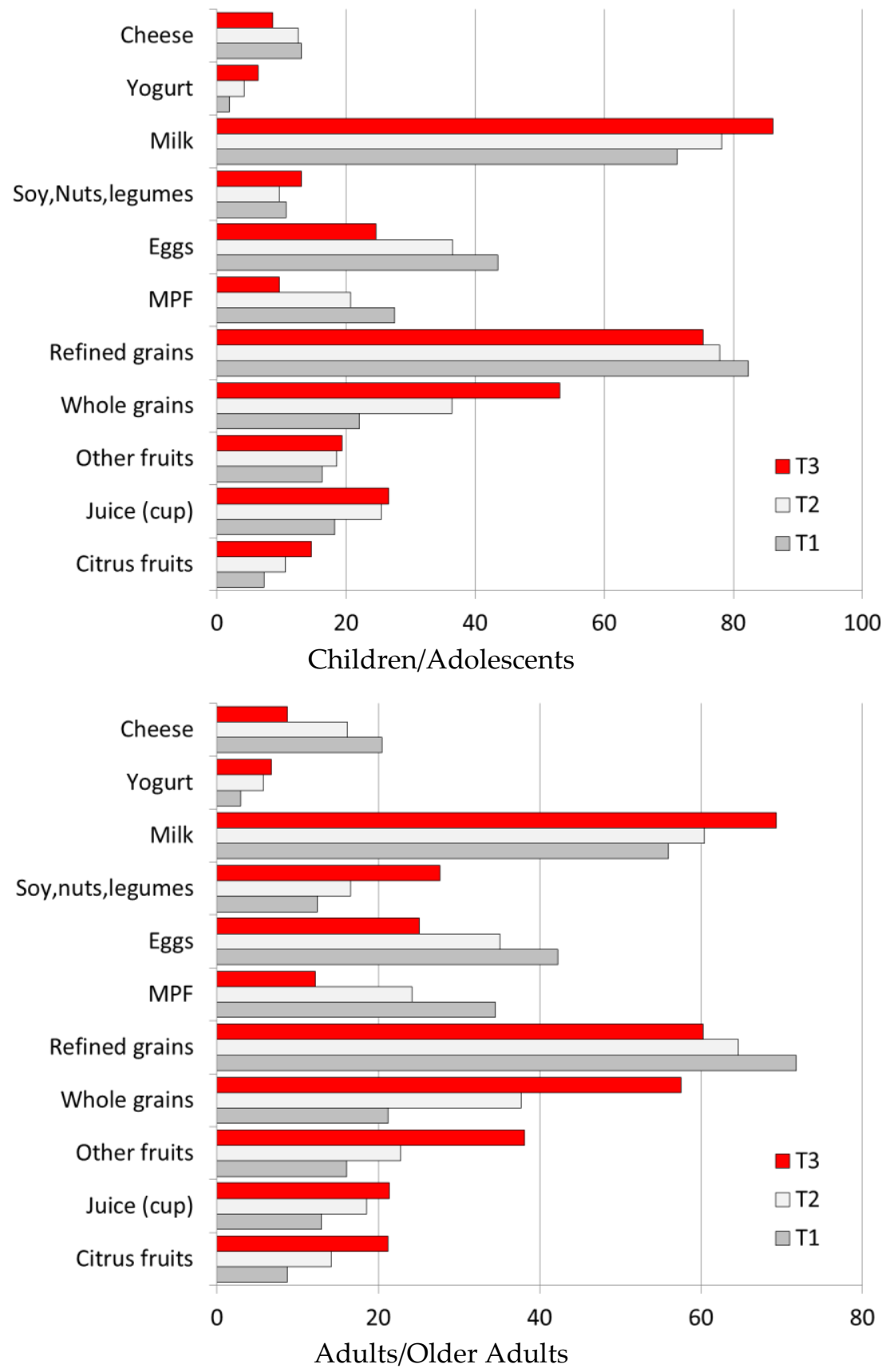

Figure 5. Percent consumers at breakfast for selected food groups by NRF9.3 tertiles. MPF stands for Meat, Poultry, Fish.

Table 4 shows the association between breakfast micronutrients and tertiles of the NRF9.3 score. As expected, there was an increase in the intake of nutrients that were in the model (protein, fiber etc.). There was also an increase in the intake of qualifying and shortfall nutrients that were not in the model. The latter include B vitamins, B12, folate and others. 
Table 4. Mean (standard error) intake of nutrients at breakfast (among consumers of breakfast only) across tertiles of NRF9.3 score by age group.

\begin{tabular}{|c|c|c|c|c|c|c|c|c|c|c|c|c|}
\hline & \multicolumn{5}{|c|}{ Children } & \multicolumn{7}{|c|}{ Adults } \\
\hline & T1 & T2 & T3 & $p^{*}$ & $p^{* *}$ & $p^{* * *}$ & T1 & T2 & T3 & $p^{*}$ & $p^{* *}$ & $p^{* * *}$ \\
\hline Ranges of NRF & {$[-568,378]$} & {$[378,506]$} & {$[506,866]$} & & & & {$[-822,376]$} & {$[376,521]$} & {$[521,878]$} & & & \\
\hline NRF9.3 & $258(5)$ & $443(2)$ & $595(3)$ & $<0.001$ & $<0.001$ & $<0.001$ & $255(2)$ & $450(1)$ & $622(2)$ & 0.0000 & $<0.001$ & $<0.001$ \\
\hline \multicolumn{13}{|c|}{ Vitamins/minerals in NRF9.3 model } \\
\hline Vitamin A, RAE (mcg) & $184(9)$ & $242(9)$ & $294(8)$ & $<0.001$ & $<0.001$ & $<0.001$ & $158(8)$ & $212(7)$ & $306(15)$ & $<0.001$ & $<0.001$ & $<0.001$ \\
\hline Vitamin C (mg) & $13(1)$ & $24(2)$ & $28(2)$ & $<0.001$ & $<0.001$ & $<0.001$ & $13(1)$ & $24(2)$ & $35(2)$ & $<0.001$ & $<0.001$ & $<0.001$ \\
\hline Vitamin D (mcg) & $2(0.1)$ & $3(0.1)$ & $3(0.1)$ & $<0.001$ & $<0.001$ & $<0.001$ & $2(0.1)$ & $2(0.1)$ & $3(0.1)$ & $<0.001$ & $<0.001$ & $<0.001$ \\
\hline Calcium (mg) & $242(10)$ & $312(12)$ & $372(9)$ & $<0.001$ & $<0.001$ & $<0.001$ & $212(5)$ & $268(7)$ & $348(6)$ & $<0.001$ & $<0.001$ & $<0.001$ \\
\hline Potassium (mg) & 415 (14) & $529(18)$ & $581(12)$ & $<0.001$ & $<0.001$ & $<0.001$ & $540(10)$ & $640(13)$ & 789 (15) & $<0.001$ & $<0.001$ & $<0.001$ \\
\hline Magnesium (mg) & $44(1)$ & $53(1)$ & $64(2)$ & $<0.001$ & $<0.001$ & $<0.001$ & $57(1)$ & $70(1)$ & $95(2)$ & $<0.001$ & $<0.001$ & $<0.001$ \\
\hline Sodium (mg) & $656(24)$ & $572(23)$ & $455(15)$ & $<0.001$ & $<0.001$ & $<0.001$ & $784(20)$ & $677(22)$ & $507(10)$ & $<0.001$ & $<0.001$ & $<0.001$ \\
\hline \multicolumn{13}{|c|}{ Vitamins/minerals not in the NRF9.3 model } \\
\hline Retinol (mcg) & $180(10)$ & $235(9)$ & $281(7)$ & $<0.001$ & $<0.001$ & $<0.001$ & $150(8)$ & $196(7)$ & $264(6)$ & $<0.001$ & $<0.001$ & $<0.001$ \\
\hline Thiamin (mg) & $0.4(0.01)$ & $0.5(0.02)$ & $0.6(0.02)$ & $<0.001$ & $<0.001$ & $<0.001$ & $0.4(0.01)$ & $0.5(0.01)$ & $0.6(0.01)$ & $<0.001$ & $<0.001$ & $<0.001$ \\
\hline Riboflavin (mg) & $0.6(0.02)$ & $0.7(0.02)$ & $0.9(0.02)$ & $<0.001$ & $<0.001$ & $<0.001$ & $0.7(0.02)$ & $0.8(0.01)$ & $0.9(0.01)$ & $<0.001$ & $<0.001$ & $<0.001$ \\
\hline Niacin $(\mathrm{mg})$ & $5(0.2)$ & $6(0.2)$ & $6(0.2)$ & $<0.001$ & $<0.001$ & $<0.001$ & $6(0.2)$ & $6(0.1)$ & $7(0.2)$ & 0.0010 & $<0.001$ & $<0.001$ \\
\hline Vitamin B6 (mg) & $0.4(0.02)$ & $0.6(0.03)$ & $0.7(0.03)$ & $<0.001$ & $<0.001$ & $<0.001$ & $0.5(0.02)$ & $0.6(0.02)$ & $0.8(0.02)$ & $<0.001$ & $<0.001$ & $<0.001$ \\
\hline Folate, DFE (mcg) & $159(9)$ & $195(10)$ & $258(12)$ & $<0.001$ & $<0.001$ & $<0.001$ & $135(6)$ & $181(5)$ & $265(10)$ & $<0.001$ & $<0.001$ & $<0.001$ \\
\hline Total folates (mcg) & $107(6)$ & $130(6)$ & $167(7)$ & $<0.001$ & $<0.001$ & $<0.001$ & $96(4)$ & $128(3)$ & $180(6)$ & $<0.001$ & $<0.001$ & $<0.001$ \\
\hline Phosphorus (mg) & 301 (11) & $329(12)$ & $352(6)$ & 0.0005 & $<0.001$ & $<0.001$ & $318(7)$ & $339(7)$ & $381(8)$ & $<0.001$ & $<0.001$ & $<0.001$ \\
\hline Zinc (mg) & $2(0.1)$ & $3(0.1)$ & $4(0.1)$ & $<0.001$ & $<0.001$ & $<0.001$ & $2(0.1)$ & $3(0.07)$ & $4(0.1)$ & $<0.001$ & $<0.001$ & $<0.001$ \\
\hline Copper (mg) & $0.2(0)$ & $0.2(0.01)$ & $0.2(0.01)$ & $<0.001$ & $<0.001$ & $<0.001$ & $0.2(0.01)$ & $0.3(0.01)$ & $0.3(0.01)$ & $<0.001$ & $<0.001$ & $<0.001$ \\
\hline Selenium (mcg) & $22(0.8)$ & $21(0.94)$ & $18(0.7)$ & $<0.001$ & 0.573 & 0.8552 & $27(0.6)$ & $26(0.8)$ & $24(0.9)$ & 0.0316 & $<0.001$ & $<0.001$ \\
\hline
\end{tabular}

${ }^{*} p$-Value unadjusted; ** $p$-value adjusted for energy at breakfast; ${ }^{* * *} p$-value adjusted for energy at breakfast, ethnicity, income to poverty ratio, education (adults only) and gender. 
Lastly, Figure 6 shows the most common food eaten at breakfast by US children and adults. For children, the most frequently consumed foods were milk, baked goods, sweets, whole grain RTEC, juice and whole fruit. For adults, the most frequently consumed items were coffee or tea, sweets (including sugar), baked goods, fats, white bread and whole fruit. The consumption of low fat dairy and whole grain bread was low.

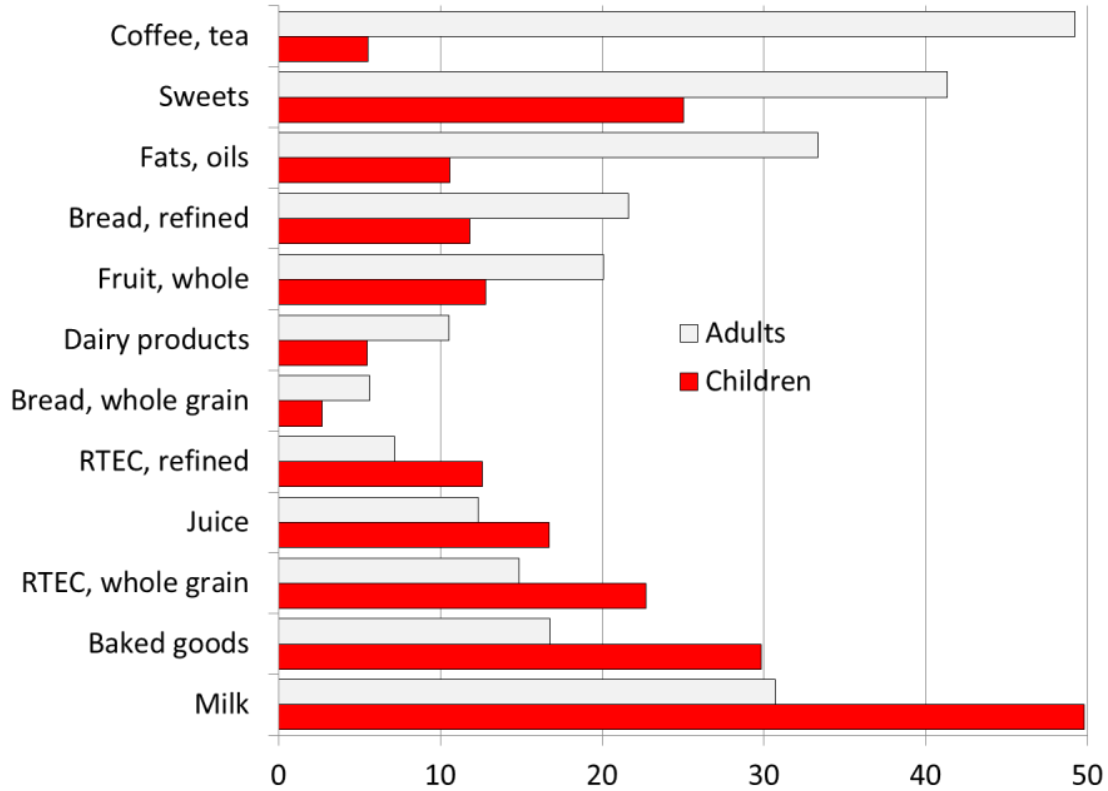

Figure 6. Percent consumers of specific food groups at breakfast by age group (data for breakfast consumers only). RTEC stands for Ready to eat cereals.

\section{Discussion}

The present analyses of first-day data from the 2011-2014 NHANES data asked what breakfast food patterns were associated with most nutrient-rich diets $[1,4,6,19,36]$ ? Shifting the focus from individual nutrients to food choices and food patterns can pave the way for future food-based dietary recommendations and guidelines. The 2015 Dietary Guidelines Advisory Committee has already delineated the relation between food patterns and health outcomes [29]; the emphasis on healthy food choices and healthy food patterns is likely to continue.

First, breakfast consumption contributed to overall DQ. Four out of 5 of NHANES participants in the 2011-2014 database ate breakfast on the first day of dietary data collection. Breakfast consumption was associated with higher socioeconomic status and also with higher-quality diets. NRF9.3 scores were higher for breakfast consumers than for non-consumers for every age group. Breakfast skipping was associated with lower education and incomes, themselves predictors of lower-quality diets and impaired health [37]. Many previous studies have pointed to associations between breakfast skipping and unfavorable health outcomes [13,14,38-42].

Among breakfast consumers, breakfast provided about $20 \%$ of daily energy, depending on age. Many micronutrients, vitamins and minerals were provided in amounts exceeding $20 \%$ of daily intakes. The definition of nutrient density in the 2005 Dietary Guidelines [43] defined nutrient dense foods as those containing "more nutrients than calories." Based on a simple nutrients-to-energy ratio, breakfast can be considered a nutrient rich meal. Depending on age, breakfast provided $>20 \%$ of daily carbohydrate and total sugar and approximately $20 \%$ of protein and fats.

The Nutrient Rich Foods Index (NRF9.3), adapted for use with total diets was the principal measure of DQ. As expected, DQ improved with age. Consistent with past studies, NRF9.3 scores were associated with higher education and incomes. Asians had the highest NRF9.3 scores; non-Hispanic Blacks had the lowest. In past studies, HEI 2010 scores were likewise associated with higher SES. 
Diets that scored in the top NRF9.3 tertile were associated with higher intakes of some key nutrients, including those that were in the model and some that were not. Diets in the top NRF9.3 tertile were also associated with higher consumption of some desirable food groups and with a higher prevalence of their consumption. The present conclusion is that the NRF9.3 nutrient density score, initially developed to capture nutrient density of individual foods, also captured nutrient density of the total diet. As expected, higher NRF scores were associated with higher SES. The SES gradient in diet quality was significant for adults but not for children and teenagers.

Even though the typical US breakfast breakfasts provided more nutrients than calories, there was room for improvement in breakfast quality. For children, the typical breakfast foods were milk, baked goods and sweets. Whole grain RTEC and whole fruit further down on the list. Adult breakfast foods included coffee/tea, sweets, fats and white bread. The present analyses allowed us to identify those food choices and breakfast patterns that were associated with highest quality diets, as captured by NRF9.3 scores. Among adults, those optimal patterns were characterized by higher intakes of citrus fruit, whole fruit and juice, soy, nuts and legumes. Among children, the optimal breakfast patterns were characterized by higher intakes of whole grain cereals, more milk and yogurt and by lower intakes of animal protein, less meat, eggs and saturated fats.

The food- and nutrient-based approach to the optimum breakfast is consistent with federal guidelines. The current federal guidelines for nutrition standards in the national school lunch and school breakfast program are both food and nutrient based. Their goal was to provide nutrient rich meals (high in nutrients and low in calories) to meet the dietary needs of schoolchildren. Rules to reduce sodium, saturated fat and trans fat were accompanied by rules to increase the availability of fruits, vegetables, whole grains and skim and low-fat milk on the school menus [44].

The present results, showing that the optimum breakfast was higher in fruit and juice, whole grain cereals and milk and yogurt, have implications for future dietary recommendations and guidelines. The IBRI dietary analyses deliberately focused on breakfast food groups and food categories in addition to individual nutrients. The 2020 Dietary Guidelines for Americans will most likely continue to focus on food patterns, showing how culturally different food patterns can result in nutrient rich meals. Nutrient profiling will most likely follow suit. Whereas most existing nutrient density scores are based on nutrients alone [27], future nutrient profiling models may take a hybrid approach, one that includes desirable foods or food groups alongside nutrients to encourage and nutrients to limit. Such desirable food groups may include fruits, nuts, seeds, whole grains and low-fat dairy. The notion of what constitutes a healthy food is being revisited by the US Food and Drug Administration.

The limitations of this study are worth noting. First, all population based dietary data in the US and the 5 other countries were based on self-report. While self-reports may not reflect true dietary intakes, the fact is that most representative population based dietary intake data globally are based on self-report. Second, data analyses were based on the first day of the 2-day NHANES survey. One day recalls are a reliable way to assess nutrient intakes of populations but do not capture the habitual dietary patterns of the individual. Better able to address habitual dietary patterns are the national dietary surveys in France, based on 7-day diaries and those in the UK, based on 4 days. Third, the breakfast meal was defined by self-report (breakfast or brunch) as opposed to the time of day. In some past studies, the timing of the meal served to define breakfast. Fourth, the food groups of interest were based on a limited number of MyPlate food categories. Finally, the modeling of an optimum breakfast would benefit from formal diet optimization methods such as linear programming.

\section{Conclusions}

The present analyses showed that the American breakfast was already a nutrient dense meal; however, there is room for improvement. While providing $20 \%$ of daily energy, breakfast provided higher amounts of key micronutrients. Diet quality of breakfast consumers, assessed using the NRF9.3 score for diets showed that higher diet quality NRF9.3 tertiles were associated with greater consumption of nutrients and food groups of interest. 
Author Contributions: C.D.R., F.V. and A.D. conceptualized and designed the study. C.D.R. developed the databases. F.V. carried out the analyses and produced summary tables. All authors reviewed and revised the manuscript and approved the final manuscript as submitted. A.D. drafted the initial manuscript and approved the final manuscript as submitted.

Funding: Cereal Partners Worldwide, Orbe, Switzerland funded the work of the International Breakfast Research Initiative and funded the publication of a series of papers in open access journals. General Mills Inc. funded analyses of publicly available US and Canadian data. The funder played no role in data collection, constriction of variables, statistical data analysis or interpretation of results.

Acknowledgments: The analyses of federal data were supported by the General Mills Bell Institute of Health and Nutrition. The sponsor had no role in the design and conduct of the study; the collection, management, analysis and interpretation of the data; or the preparation or approval of the manuscript. C.D.R. and F.V. had full access to all of the data in the study and take responsibility for the integrity of the data and the accuracy of the data analysis. A.D. has received grants, honoraria and consulting fees from numerous food and beverage companies and other commercial and nonprofit entities with interests in nutrient density of the diet. C.D.R. has no conflict of interest to declare. F.V. is employee of MS-Nutrition.

Conflicts of Interest: Authors have received funding from General Mills Inc. for analyses of publicly available NHANES datasets and for their contribution to the project. Adam Drewnowski has received grants, contracts, honoraria and consulting fees from numerous food and beverage companies and other commercial and nonprofit entities with interests in diet quality and health.

\section{References}

1. Afeiche, M.C.; Taillie, L.S.; Hopkins, S.; Eldridge, A.L.; Popkin, B.M. Breakfast dietary patterns among mexican children are related to total-day diet quality-3. J. Nutr. 2017, 147, 404-412. [CrossRef] [PubMed]

2. Betts, J.A.; Chowdhury, E.A.; Gonzalez, J.T.; Richardson, J.D.; Tsintzas, K.; Thompson, D. Is breakfast the most important meal of the day? Proc. Nutr. Soc. 2016, 75, 464-474. [CrossRef] [PubMed]

3. Kant, A.K.; Andon, M.B.; Angelopoulos, T.J.; Rippe, J.M. Association of breakfast energy density with diet quality and body mass index in american adults: National health and nutrition examination surveys, 1999-2004. Am. J. Clin. Nutr. 2008, 88, 1396-1404. [PubMed]

4. O'Neil, C.E.; Nicklas, T.A.; Fulgoni, V.L., III. Nutrient intake, diet quality, and weight/adiposity parameters in breakfast patterns compared with no breakfast in adults: National health and nutrition examination survey 2001-2008. J. Acad. Nutr. Diet. 2014, 114, S27-S43. [CrossRef] [PubMed]

5. Coulthard, J.D.; Palla, L.; Pot, G.K. Breakfast consumption and nutrient intakes in 4-18-year-olds: UK national diet and nutrition survey rolling programme (2008-2012). Br. J. Nutr. 2017, 118, 280-290. [CrossRef] [PubMed]

6. Hopkins, L.C.; Sattler, M.; Steeves, E.A.; Jones-Smith, J.C.; Gittelsohn, J. Breakfast consumption frequency and its relationships to overall diet quality, using healthy eating index 2010, and body mass index among adolescents in a low-income urban setting. Ecol. Food Nutr. 2017, 56, 297-311. [CrossRef] [PubMed]

7. Bi, H.; Gan, Y.; Yang, C.; Chen, Y.; Tong, X.; Lu, Z. Breakfast skipping and the risk of type 2 diabetes: A meta-analysis of observational studies. Public Health Nutr. 2015, 18, 3013-3019. [CrossRef] [PubMed]

8. Burazeri, G.; Hyska, J.; Mone, I.; Roshi, E. Breakfast skipping is an independent predictor of obesity but not overweight among children in a southeastern European population. Int. J. Vitam. Nutr. Res. 2016, 1, 1-7. [CrossRef] [PubMed]

9. Pendergast, F.J.; Livingstone, K.M.; Worsley, A.; McNaughton, S.A. Correlates of meal skipping in young adults: A systematic review. Int. J. Behav. Nutr. Phys. Act. 2016, 13, 125. [CrossRef] [PubMed]

10. Okada, C.; Tabuchi, T.; Iso, H. Association between skipping breakfast in parents and children and childhood overweight/obesity among children: A nationwide 10.5-year prospective study in Japan. Int. J. Obes. 2018. [CrossRef] [PubMed]

11. Otaki, N.; Obayashi, K.; Saeki, K.; Kitagawa, M.; Tone, N.; Kurumatani, N. Relationship between breakfast skipping and obesity among elderly: Cross-sectional analysis of the Heijo-Kyo study. J. Nutr. Health Aging 2017, 21, 501-504. [CrossRef] [PubMed]

12. Fayet-Moore, F.; McConnell, A.; Kim, J.; Mathias, K.C. Identifying eating occasion-based opportunities to improve the overall diets of Australian adolescents. Nutrients 2017, 9, 608. [CrossRef] [PubMed]

13. Papoutsou, S.; Briassoulis, G.; Wolters, M.; Peplies, J.; Iacoviello, L.; Eiben, G.; Veidebaum, T.; Molnar, D.; Russo, P.; Michels, N.; et al. No breakfast at home: Association with cardiovascular disease risk factors in childhood. Eur. J. Clin. Nutr. 2014, 68, 829-834. [CrossRef] [PubMed] 
14. Van der Heijden, A.A.; Hu, F.B.; Rimm, E.B.; van Dam, R.M. A prospective study of breakfast consumption and weight gain among U.S. Men. Obesity 2007, 15, 2463-2469. [CrossRef] [PubMed]

15. Kant, A.K.; Graubard, B.I. Within-person comparison of eating behaviors, time of eating, and dietary intake on days with and without breakfast: Nhanes 2005-2010-3. Am. J. Clin. Nutr. 2015, 102, 661-670. [CrossRef] [PubMed]

16. Albertson, A.M.; Wold, A.C.; Joshi, N. Ready-to-eat cereal consumption patterns: The relationship to nutrient intake, whole grain intake, and body mass index in an older American population. J. Aging Res. 2012, 2012, 631310. [CrossRef] [PubMed]

17. Bazzano, L.A.; Song, Y.; Bubes, V.; Good, C.K.; Manson, J.E.; Liu, S. Dietary intake of whole and refined grain breakfast cereals and weight gain in men. Obes. Res. 2005, 13, 1952-1960. [CrossRef] [PubMed]

18. Djoussé, L.; Gaziano, J.M. Breakfast cereals and risk of heart failure in the physicians' health study i. Arch. Intern. Med. 2007, 167, 2080-2085. [CrossRef] [PubMed]

19. Rehm, C.D.; Drewnowski, A. Replacing American breakfast foods with ready-to-eat (rte) cereals increases consumption of key food groups and nutrients among us children and adults: Results of an Nhanes modeling study. Nutrients 2017, 9, 1010. [CrossRef] [PubMed]

20. Koca, T.; Akcam, M.; Serdaroglu, F.; Dereci, S. Breakfast habits, dairy product consumption, physical activity, and their associations with body mass index in children aged 6-18. Eur. J. Pediatr. 2017, 176, 1251-1257. [CrossRef] [PubMed]

21. Lepicard, E.; Maillot, M.; Vieux, F.; Viltard, M.; Bonnet, F. Quantitative and qualitative analysis of breakfast nutritional composition in french schoolchildren aged 9-11 years. J. Hum. Nutr. Diet. 2017, 30, 151-158. [CrossRef] [PubMed]

22. Center for Disease Control (CDC); National Center for Health Statistics. About the National Health and Nutrition Exmaination Survey (Nhanes). Available online: http://www.cdc.gov/nchs/nhanes/about_ nhanes.htm (accessed on 30 August 2018).

23. Centers for Disease Control and Prevention (CDC); National Center for Health Statistics. Questionnaires, Datasets, and Related Documentation. Available online: https://wwwn.cdc.gov/nchs/nhanes/Default.aspx (accessed on 30 August 2018).

24. Drewnowski, A. The nutrient rich foods index helps to identify healthy, affordable foods. Am. J. Clin. Nutr. 2010, 91, S1095-S1101. [CrossRef] [PubMed]

25. Francou, A.; Hebel, P.; Braesco, V.; Drewnowski, A. Consumption patterns of fruit and vegetable juices and dietary nutrient density among french children and adults. Nutrients 2015, 7, 6073-6087. [CrossRef] [PubMed]

26. Drewnowski, A. Nutrient density and health: How to develop global nutrient density metrics. In Preventive Nutrition; Springer: Berlin, Germany, 2015; pp. 71-81.

27. Drewnowski, A.; Fulgoni, V.L., III. Nutrient density: Principles and evaluation tools. Am. J. Clin. Nutr. 2014, 99, S1223-S1228. [CrossRef] [PubMed]

28. Hill, K.M.; Jonnalagadda, S.S.; Albertson, A.M.; Joshi, N.A.; Weaver, C.M. Top food sources contributing to vitamin $\mathrm{d}$ intake and the association of ready-to-eat cereal and breakfast consumption habits to vitamin $\mathrm{d}$ intake in Canadians and united states Americans. J. Food Sci. 2012, 77, H170-H175. [CrossRef] [PubMed]

29. US Department of Health Human Services. Dietary Guidelines for Americans 2015-2020; Skyhorse Publishing Inc.: New York, NY, USA, 2017.

30. Calvo, M.S.; Lamberg-Allardt, C.J. Vitamin d research and public health nutrition: A current perspective. Public Health Nutr. 2017, 20, 1713-1717. [CrossRef] [PubMed]

31. National Cancer Institute, Division of Cancer Control and Population Sciences. Comparing the hei-2015, hei-2010 \& hei-2005. Available online: https:/ / epi.grants.cancer.gov/hei/comparing.html (accessed on 30 August 2018).

32. Bowman, S.; Clemens, J.; Friday, J.; Thoerig, R.; Moshfegh, A. Food Patterns Equivalents Database 2011-12: Methodology and User Guide; Food Surveys Research Group: Beltsville, MD, USA, 2014.

33. Centers for Disease Control and Prevention (CDC); National Center for Health Statistics. Nchs Research Ethics Review Board (erb) Approval. Available online: http://www.cdc.gov/nchs/nhanes/irba98.htm (accessed on 30 August 2018).

34. Hiza, H.A.; Casavale, K.O.; Guenther, P.M.; Davis, C.A. Diet quality of americans differs by age, sex, race/ethnicity, income, and education level. J. Acad. Nutr. Diet. 2013, 113, 297-306. [CrossRef] [PubMed] 
35. Garriguet, D. Diet quality in Canada. Health Rep. 2009, 20, 41-52. [PubMed]

36. Williams, B.M.; O’Neil, C.E.; Keast, D.R.; Cho, S.; Nicklas, T.A. Are breakfast consumption patterns associated with weight status and nutrient adequacy in african-american children? Public Health Nutr. 2009, 12, 489-496. [CrossRef] [PubMed]

37. Drewnowski, A.; Specter, S.E. Poverty and obesity: The role of energy density and energy costs. Am. J. Clin. Nutr. 2004, 79, 6-16. [CrossRef] [PubMed]

38. Rodrigues, P.R.M.; Luiz, R.R.; Monteiro, L.S.; Ferreira, M.G.; Goncalves-Silva, R.M.V.; Pereira, R.A. Adolescents' unhealthy eating habits are associated with meal skipping. Nutrition 2017, 42, 114-120. [CrossRef] [PubMed]

39. Smith, K.J.; Breslin, M.C.; McNaughton, S.A.; Gall, S.L.; Blizzard, L.; Venn, A.J. Skipping breakfast among australian children and adolescents; findings from the 2011-12 national nutrition and physical activity survey. Aust. N. Z. J. Public Health 2017, 41, 572-578. [CrossRef] [PubMed]

40. Tee, E.S.; Nurliyana, A.R.; Norimah, A.K.; Mohamed, H.; Tan, S.Y.; Appukutty, M.; Hopkins, S.; Thielecke, F.; Ong, M.K.; Ning, C.; et al. Breakfast consumption among malaysian primary and secondary school children and relationship with body weight status-Findings from the mybreakfast study. Asia Pac. J. Clin. Nutr. 2018, 27, 421-432. [PubMed]

41. Traub, M.; Lauer, R.; Kesztyus, T.; Wartha, O.; Steinacker, J.M.; Kesztyus, D. Skipping breakfast, overconsumption of soft drinks and screen media: Longitudinal analysis of the combined influence on weight development in primary schoolchildren. BMC Public Health 2018, 18, 363. [CrossRef] [PubMed]

42. Zhang, L.; Cordeiro, L.S.; Liu, J.; Ma, Y. The association between breakfast skipping and body weight, nutrient intake, and metabolic measures among participants with metabolic syndrome. Nutrients 2017, 9, 384. [CrossRef] [PubMed]

43. Diietary Guidelines for Americans 2015-2020. Available online: https://health.gov/dietaryguidelines/ 2015/guidelines/ (accessed on 30 August 2018).

44. US Department of Agriculture, Food and Nutrition Service. Nutrition Standards in the National School Lunch and School Breakfast Programs. Federal Register/Vol. 77, No. 17/January 26, 2012/Rules and Regulations. Available online: https:/ /www.gpo.gov/fdsys/pkg/FR-2012-01-26/pdf/2012-1010.pdf (accessed on 30 August 2018).

(C) 2018 by the authors. Licensee MDPI, Basel, Switzerland. This article is an open access article distributed under the terms and conditions of the Creative Commons Attribution (CC BY) license (http:/ / creativecommons.org/licenses/by/4.0/). 